\title{
What faculty have to say about library outreach \\ A rural community college survey
}

J ust what are faculty looking for when it comes to library outreach? With relatively little formal research available that asks faculty directly about their needs and preferences when it comes to outreach activities, I decided to ask the faculty of a rural community college this question directly using a formal, but low-stakes, survey.

\section{Background on Coconino Community College}

Coconino Community College (CCC) is a public, two-year college based in Flagstaff, Arizona. In 2010, the college closed its oncampus library, instead focusing its limited resources on maintaining a single librarian and library database subscriptions. ${ }^{1}$ Community college users have access to some library services at nearby Northern Arizona University, including access to print books, study rooms, and computers. ${ }^{2}$ While many librarians emphasize outreach as part of their service to the academic community, these duties take on particular importance with a nontraditional library model.

I spent January 2013 through January 2016 as the CCC library and learning resources coordinator. Success in this unique position relied on constant outreach to faculty, students, and stakeholders. To quote Estelle Pope, ${ }^{3}$ the librarian who preceded me in this position, in this case, "connections and new collaborations represent the college library." "This reliance of outreach makes CCC a worthwhile setting in which to ask faculty about librarian outreach. Furthermore, since the librarian position at CCC was vacant for several months after my departure, it is particularly interesting to have faculty consider library outreach during a period in which no formal outreach programs are in place on campus.

\section{About library outreach: What others have found, what I tried}

Relatively little research is present in the LIS literature that asks faculty directly about their perspective on library outreach. Through a literature review, Kristin Anthony found librarians could become colleagues of faculty by "taking the time to attend faculty meetings and to interest themselves in faculty research projects." Regularly attending faculty meetings is an initiative I undertook, particularly in my final year at CCC, as a way of connecting with unreached or underserved academic departments.

Margaret Bausman and her coauthors used surveys to assess faculty awareness and use of services and resources available from Hunter College libraries. ${ }^{6}$ They found "no relationship between tenure status and

Nick Faulk, formerly of Coconino Community College, is digital learning librarian at Champlain College, email: nfaulk@champlain.edu

ㅇ 2018 Nick Faulk 
awareness of services." Despite this, it is particularly important to remain cognizant of the needs of part-time faculty. Margaret Avery argued that the necessity of building relationships with part-time faculty "falls on librarians" and points to a variety of characteristics of successful part-time faculty outreach programs, including off-hours librarian availability and adjunct-focused guides and toolkits. $^{8}$

Finding the flexibility to provide off-hours availability is a particular challenge for the solo librarian, though one step I took to this effect was to maintain a 9 a.m. to 6 p.m. work schedule. Ultimately, my library outreach efforts were heavily focused on emails, flyers, and building relationships with new faculty during the on-boarding process.

With this background reading in mind, I decided to ask CCC faculty at about their perceptions of the best outreach techniques for promoting library services and resources.

\section{The survey to faculty}

I arranged for part-time and full-time faculty to receive a five-question survey that asked participants to consider outreach techniques for library resources and library services. Two questions were open-ended, eliciting opinions on the promotion of new resources and on communication practices. The three remaining questions considered part-time versus full-time status, number of years of employment at the college, and level of contact with the college's librarian in the past year. Fourteen faculty members chose to participate: nine during the first round of surveys in May 2016 and five more during a September 2016 redistribution of the survey. To better understand the results, I used open coding to analyze the survey responses, interpreting the raw responses into a few key takeaway messages easily applicable to everyday outreach activities.

\section{What I learned}

Key findings for resource adoption: Awareness, ease of use, and time for review
Faculty are interested in developing their awareness of the information landscape but want to know a resource's connection to their curriculum before adoption. The majority of participants (64\%) cited the importance of outreach activities in creating awareness of library resources. A feeling that there were resources in the library or elsewhere that they are not using came up for multiple participants. As part of that awareness building, faculty want to know how specifically a resource connects to their instructional context and look for outreach that makes that connection for them (a need that was cited by two participants). Ultimately, many faculty trust librarians and will listen to our recommendations. As one faculty member who responded to the survey said: "If the librarian suggested it, I would use it!"

Ease of use emerged as a factor that plays into a resource's adoption for faculty, with two participants citing that as a key factor for adoption into their curriculum, with one participant noting the related concept of finding the time to explore a resource was also at play. Faculty reported a desire for support in the form of demonstrations when being introduced to a resource for the first time, whether that demonstration be one-on-one or in the classroom. With this in mind, effective outreach campaigns might emphasize the convenience or user-focused design of a resource while also pointing faculty in the direction of support available for them and their students.

Faculty need time and space to review a resource adoption, with multiple participants citing the opportunity to explore a resource on their own terms to be a key factor in its adoption. As one participant reminded us, the "librarian must understand the perspective from which I make decisions," which suggests that taking the time to have conversations with faculty about their review process before beginning an outreach campaign would be beneficial.

\section{Key findings for communication meth- ods: Keep it simple}

Faculty look for communication that is clear 
and simple. About half of participating faculty reported an interest in outreach that is descriptive yet to the point. One participant noted that they want to understand the purpose of any written outreach communication in its first paragraph, citing a desire not to "have to wade through paragraphs trying to figure it out." Some participants stated a need for outreach communications to make connections to their goals as instructors, while others said that effective outreach should connect services and resources with the needs of students.

When conducting outreach, some instructors place a premium on in-person discussion (14\%), while others prefer email (43\%), and others still are looking to learn about new services with their students during an in-class visit (29\%). So mixed methods that reach different faculty in different ways are likely to be the most effective.

\section{Implications of the survey results in my current role}

Despite the fact that I have moved to a new library and my current job has a less explicit outreach role, there have been several ways in which I have been able to use these findings to shape my interaction with faculty. In my current role at Champlain College, I am designing an information literacy program for students enrolled in our online undergraduate programs. This program takes the form of reusable learning objects embedded into courses across the curriculum and taught by the faculty of record for each class. Developing and deploying these modules requires collaboration and buy in from division faculty, particularly part-time faculty who live at a distance. This makes email a particularly important communication technique, and I have worked to keep my messages short when possible, and heed the advice from the survey respondent who reported that they like to know the purpose of an email in its first paragraph. When a lengthier conversation is necessary, I have arranged a video conferencing appointment with the faculty member.

\section{As one faculty member who respond- ed to the survey said: "If the librarian suggested it, I would use it!"}

The trust that many faculty place in librarians in resource selection seems to extend into information literacy instructional design, at least in the context of this project. When conducting pilots of proposed lessons in single sections of a class, I have consistently found that the faculty member identified by their division dean are both excited to participate and willing to defer to my lesson design and chosen learning outcomes. Obtaining indepth feedback from faculty already teaching a lesson has proven more difficult, which may again speak to the trust that faculty have in librarians, or it may suggest that these particular faculty members do not see the calls for feedback as sufficiently tied to their goals or the needs of their students.

\section{Future directions for research and exploration}

More formal research on this topic would benefit from larger study populations in order to collect a more representative sample. Alternatively, because most responses to the open-ended question portion of the survey instrument were quite short (the majority were one sentence or less), a series of interviews with faculty might produce answers of more depth, resulting in findings that are more specific. In the interest of ensuring participant anonymity, demographic data was only collected about part-time versus full-time employment status and years of service to the college, meaning that there could be gaps in this data revealed by participants' subjects taught, instructional modality, or educational background. Finally, knowing that faculty place a premium on communication that is quick and clear but that individuals express preferences for different modalities, research that compares faculty responses to specific outreach situations would likely prove illuminating. 


\section{Acknowledgements}

Thank you to Michael Merica, director of Institutional Research at CCC, for assisting with the distribution of this survey to college faculty.

\section{Notes}

1. Hillary Davis, "CCC Closes Flagstaff Campus Library," Arizona Daily Sun, April 13, 2010, http://azdailysun.com/news /local/education/ccc-closes-flagstaff-campus -library/article_5e15a392-aeb9-5267-9ddd -afdb063ba1a7.html.

2. "CCC Library," Coconino Community College, last modified 2016, www.coconino. edu/library.

3. Estelle Pope, "The New Coconino Community College Library: A Librarian, Collaborative Library Services, and an Online
Library," in How to Thrive as a Solo Librarian, eds. Carol Smallwood and Melissa J. Clapp (Lanham: Rowman \& Littlefield, 2012), 163-71.

4. Pope, "The New Coconino Community College Library," 163.

5. Kristin Anthony, "Reconnecting the Disconnects: Library Outreach to Faculty as Addressed in the Literature," College \& Undergraduate Libraries 17, no. 1 (2010): 91.

6. Margaret Bausman, Sarah Laleman Ward, and John Pell, "Beyond Satisfaction: Understanding and Promoting the InstructorLibrarian Relationship," New Review of Academic Librarianship 20 no. 2 (2014): 129.

7. Ibid.

8. Susan Avery, "Adjunct Faculty and the Library: A Challenge for Change," College $\varepsilon$ Undergraduate Libraries 20, no. 1 (2013): 36-37. $\neq 2$

("Teaching FYI," continues from page 192)

of students who received library instruction through the Canvas tutorials to those whose library instruction consisted of the traditional library one-shot session. We also incorporated an active learning information literacy session that focused on evaluating information sources.

One session, which we have informally titled "Using the Credibility Continuum," proved to be helpful in giving students a greater understanding of the types of sources that they are likely to encounter while doing research. For this lesson, we brought a box filled with an assortment of 20 items from the library collection to class. The goal was to encourage hands-on evaluations of sources, including credibility, audience, author credentials, academic journals versus online articles, websites, and DVD documentaries. In class, each student is given a source and is asked to evaluate it using the credibility continuum and the CRAAP test. ${ }^{1}$ This led to very good classroom discussions on the types of information found in different sources, and the similarities in evaluating both hard-copy and electronic sources. We plan to market this active learning activity to additional classes in hopes of increasing students' understanding of information literacy.

\section{Conclusion}

Overall we have enjoyed the experience of working with students in the classroom. We felt that one of the most beneficial aspects was the ability to see students using their skills "in the wild" and not when they are being guided by us at the reference desk or in library instruction. Our experience teaching FYI has provided us with a better understanding of first-year students' mindsets and research habits. We hope that this experience has also enabled us to devise a more effective library instruction program for first-year students. Our experiences have reinforced the importance of active learning in the classroom and the necessity of additional library review sessions beyond the one-shot.

\section{Note}

1. http://libguides.franklinpierce.edu /credibility, a LibGuide created by Franklin Pierce University Librarians. $\neq 2$ 